\title{
Greenspaces planning evolution in Madrid in the 20th century
}

\author{
M. J. García ${ }^{1}$, A. I. García ${ }^{1}$ \& A. D. J. Atkinson ${ }^{2}$ \\ ${ }^{I}$ Departamento de Proyectos y Planificación Rural, \\ Universidad Politecnica de Madrid, España \\ ${ }^{2}$ Departamento de Expresión Gráfica, Universidad de Extremadura, \\ España
}

\begin{abstract}
The present work is an investigation of what occurred in Madrid during the 20th century with respect to greenspace design and planning. The study begins with the city's first urban plan, the "Plan de Ensanche", drafted in 1857 by Carlos María de Castro. The plan which is currently in force is the "Plan General de Ordenación Urbana de Madrid" of 1997. The present study analyzes the evolution in this period of the planning and design processes of public greenspaces in the Madrid Metropolitan Area. The regulation of the existence and creation of these spaces, their public accessibility, numbers and area, location, type, and function is reflected in a succession of documents throughout the 20th century under the general denomination of "Urban Plans". These documents differ widely in the variety of topics they cover: planning objectives, treatment of achievements, the territorial scope of the plan's applicability, etc. The resulting difficulties in performing a comparative study were initially resolved by applying two urban greenspace indices - quantity of greenspaces, and square metre of greenspace per inhabitant. These allowed the various plans to be compared and their evolution analyzed. Two of the conclusions drawn from the analyses were: (i) that the proposals of greatest greenspace area corresponded to the middle third of the century, not to the end of the century as might have been expected, but that it was precisely this period that saw the lowest rate of real greenspace creation; and (ii) the enormous influence that two historical Madrid greenspaces - the Casa del Campo, and the Monte de Pardo had on the service indices throughout the century.
\end{abstract}

Keywords: landscape, urban greening, greenspace planning, Madrid. 


\section{Introduction}

The objective of the present study was to analyze the design and planning of greenspaces in Madrid during the 20th century.

A series of initial questions were posed. At what time in the century did planners give greatest importance to greenspaces. How did they do so? Do the current proposals represent much better service indices than at other times, or not? Have the quantity and quality of greenspaces always been proportional to the growth of the city and its number of inhabitants? What were the design factors taken into account at the beginning of the century? Has there been much change from then to those of today and, if so, what has changed? Has the system of greenspaces included large spaces other than parks and gardens? If so, since when?
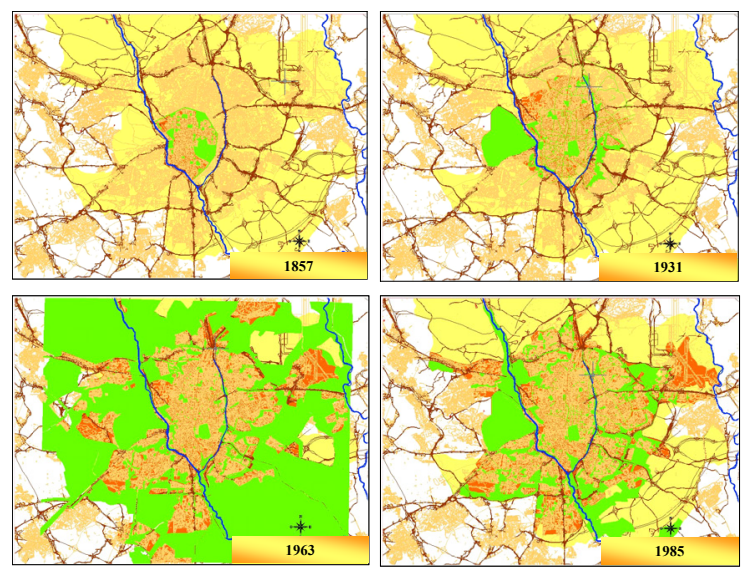

Figure 1: Examples of greenspace proposals.

There has been some previous work in the line of the present study. Alonso [1] studied certain design criteria in an overview of European and American experiences. Interesting because of their closeness to the case of Madrid are the works of Cubillo [2] in the 1970s, and later of Rodríguez-Avial [3] which expressed for the first time in Spain the idea of considering greenspaces in the city as a functional system in overall planning. An ecological approach proposed Floresta [4], and much more recently, Salvador [5] reviewed the literature on the new international trends with respect to "green planning" in cities and, above all, in metropolitan areas or, in large urban regions. Van Herzele and Widemann [6] and Bonaiuto et al [7] consider the viewpoint of citizens, Van den Dobbelsteena and de Wilde [8] has been working on indicators for space use efficiency; Zhang and Wanga [9] and Oh and Jeong [10] recently working on connectivity and accessibility of greenspaces. Nonetheless, the approach of these studies does not provide solutions to the questions raised above.

There has been a single class of instrument that has regulated greenspace design and planning in Madrid - the Urbanism Plans. Although they have been 
the subject of an extensive literature, especially at certain times of the last century, no work has analyzed these documents from the point of view of the city's greenspaces.

Thus, it seemed to be of the greatest interest to first perform an exhaustive review of all the century's Urbanism Plans in their aspect of being the instrument of forecasting and planning the greenspaces of Madrid (Figure 1). The accomplishment of this task would help to establish a series of factors with which to assess the changes that the planning of greenspaces in Madrid has undergone, and thus provide a picture of how that planning has evolved. The present communication summarizes the results of this second part of the study. In particular, the results are presented in the form of a set of indices calculated from the data contained in the Plans.

Some interesting conclusions were drawn. While the greenspace proposals for Madrid showed an overall improving evolution over the course of the century, the best proposals corresponded to mid-century, not to the end. Paradoxically, this period when planners gave the greatest importance to greenspaces was also when the actual creation of greenspace was minimal. The study also shows the enormous influence that two historical Madrid greenspaces - the Casa del Campo, and the Monte de Pardo - had on the service indices throughout the century.

\section{Methods}

We reviewed all the urban plans published for Madrid during the 20th century. We began with the "Plan de Ensanche" (Expansion Plan) of 1857 because, although it was drafted in the 19th century, it was the first Urbanism Plan established for Madrid, and remained the only one in effect until the adoption of the "Plan de Extensión" in 1931.

Following their first analysis, it was decided to evaluate the following indices:

1. Amounts of existing and of proposed greenspaces.

2. Service Index: Area of greenspace per inhabitant.

3. Percentage of greenspace relative to the total urban area.

These indices were calculated for all the Plans in which it was possible to do so, since not all the documents provided the necessary data.

The data were taken directly from consulting the original documents, either by directly extracting the numerical information expressed in them or by digitalizing reproductions of their maps. We also consulted secondary documentation, i.e., studies of the source documents. This information, however, was treated with caution, since in many cases it was impossible to verify the data provided.

A particular effort was made to systematize and homogenize the data to enable its use in the calculation of the indices. This process was essential due to the great variety in the Plans. Indeed, the treatment can almost be said to have been individual. For instance, among the most important factors that presented a great degree of variability were: (i) The territorial scope of application of the Plan, from some minor extension to the grouping of several previously 
independent municipalities into a single metropolitan area, or a change in a municipality by annexation of neighbouring municipalities. (ii) The time frame for application of the Plan. (iii) The presence or absence of a direct estimate of the inhabitants to whom the service was to be provided. (iv) The greenspace typology used, and the diversity of their consideration in the Plan.

\section{Results and discussion}

Of all the Plans analyzed, we selected those which allowed a quantitative analysis $(1857,1910,1926,1931,1946,1963,1985,1997)$. The results will be presented below in parallel with their discussion.

\subsection{Greenspace quantity index}

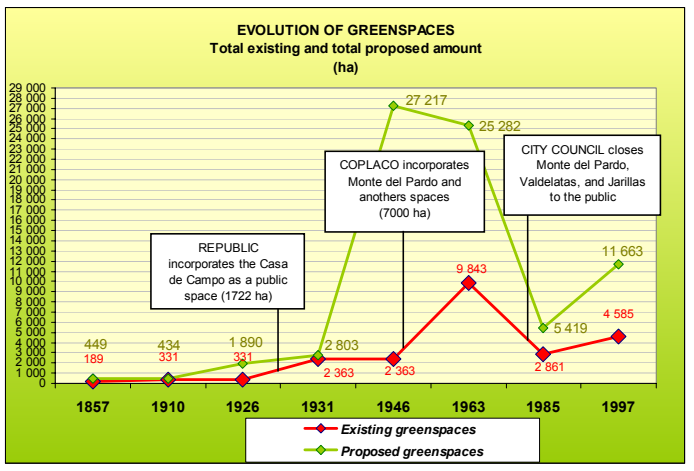

Figure 2: $\quad$ Evolution of the amount of greenspaces.

\subsubsection{Existing and proposed amounts of greenspace}

The amounts of greenspaces proposed grew over the course of the century (Table 1). The maximum, however, occurred not in the final years of the century, but in the proposals that corresponded essentially to the decades of the 1950s to the 1970s (1946-1963). This maximum size was an order of magnitude greater than the figures corresponding to the preceding and immediately following Plans. The data of the 1997 Plan return to that mid-century order of magnitude, but under very different proposals.

The evolution of the proposals contrasts sharply with the actual creation of greenspaces in those years (Table 2). Indeed, when there was an almost off-the-

Table 1: $\quad$ Proposed greenspaces.

\begin{tabular}{|c|c|c|c|c|c|c|c|c|}
\hline Proposed greenspaces (ha) & 1857 & 1910 & 1926 & 1931 & 1946 & 1963 & 1985 & 1997 \\
\hline City parks (only) & 346 & 331 & 1691 & 1040 & - & 1366 & 1849 & - \\
\hline Urban greenspaces & 449 & 434 & 1890 & 1081 & 3039 & 2969 & 3484 & 4267 \\
\hline Metropolitan greenspaces & - & - & - & 1722 & 24178 & 22313 & 1934 & 7396 \\
\hline Proposed greenspaces & 449 & 434 & 1890 & 2803 & 27217 & 25282 & 5419 & 11663 \\
\hline
\end{tabular}


scale maximum of greenspace proposals in the Plans, their real creation was at a minimum. Indeed, if one considers the population and the existing urban area, it is precisely in that period when the smallest amount of greenspace was created in Madrid.

Table 2: $\quad$ Existing greenspaces.

\begin{tabular}{|c|c|c|c|c|c|c|c|c|}
\hline Existing greenspaces (ha) & 1857 & 1910 & 1926 & 1931 & 1946 & 1963 & 1985 & 1997 \\
\hline City parks (only) & 189 & 331 & 331 & 641 & - & 1121 & 996 & - \\
\hline Urban greenspaces & 189 & 331 & 331 & 641 & 641 & 1121 & 1371 & 1885 \\
\hline Metropolitan greenspaces & - & - & - & 1722 & 1722 & 8722 & 1489 & 2699 \\
\hline Existing greenspaces & 189 & 331 & 331 & 2363 & 2363 & 9843 & 2861 & 4585 \\
\hline
\end{tabular}

\subsubsection{Increases in greenspace of "new creation"}

Data were obtained on the increase in greenspace that was actually available to Madrileños (the inhabitants of Madrid) in the inter-Plan periods, and we determined which of these additions were of new creation (Table 3). The percentage increase corresponds to the ratio between the "amount of existing greenspace of new creation" during each period and the "total amount of existing greenspace" at the beginning of the period.

Table 3: Newly created spaces.

\begin{tabular}{|l|c|c|c|c|c|c|c|c|c|}
\hline $\begin{array}{l}\text { Existing newly created greenspaces } \\
\text { (ha) }\end{array}$ & $\mathbf{1 8 5 7}$ & $\mathbf{1 9 1 0}$ & $\mathbf{1 9 2 6}$ & $\mathbf{1 9 3 1}$ & $\mathbf{1 9 4 6}$ & $\mathbf{1 9 6 3}$ & 1985 & 1997 \\
\hline Existing greenspaces & 189 & 331 & 331 & 2363 & 2363 & 9843 & 2861 & 4585 \\
\hline Newly created greenspaces & 189 & 331 & 331 & 641 & 641 & 1121 & 1139 & 2863 \\
\hline Increase new creation & & 142 & 0 & 310 & 0 & 480 & 18 & 1724 \\
\hline \% INCREASE & & $\mathbf{7 5}$ & $\mathbf{0}$ & $\mathbf{9 4}$ & $\mathbf{0}$ & $\mathbf{7 5}$ & $\mathbf{2}$ & $\mathbf{1 5 1}$ \\
\hline PERIOD & & $1857-1910$ & $1910-1926$ & $1926-1931$ & $1931-1946$ & $1946-1963$ & $1963-1985$ & $1985-1997$ \\
\hline
\end{tabular}

The surroundings of Madrid were, and still are, rich in natural spaces of great value in terms of their ecology, landscape, etc., and therefore especially attractive as greenspaces for public use. Some of these spaces were used throughout the century as proposals for integration into the city's greenspace system. Thus, even though no tree was planted, nor any public work carried out, extensive wooded areas were created as greenspaces in the sense that they were made available to Madrileños.

Between 1926 and 1931, there was an increase of 2032 ha in the amount of greenspace publicly available (Table 3 ). Of that amount, only 310 ha were of new creation. The other 1722 ha belonged to the Casa de Campo, which was Royal Property until 1931 when the First Republic ceded it to the people of Madrid (Figure 2).

Neither was any greenspace destroyed between 1963 and 1985. The decline in the amount, by 6983 ha (Table 3), was because the Madrid City Council decided to protect the Monte de Pardo (another Royal Property) as a space of high ecological value. Part of the estate (almost 7000 ha) which Madrileños had 
enjoyed for their leisure since 1963 was closed to the public, and the entire Monte de Pardo was protected by a special law.

\subsection{Service index: area of greenspace per inhabitant}

This index was aimed at describing the situation from the citizens' standpoint. Thus, we calculated (i) the area that corresponded to each citizen (Existing Service Index), (ii) what they could aspire to with the corresponding Plan (Proposed Service Index), and (iii) what the proposal represented with respect to the existing situation (Service Expectation Index).

Population growth in Madrid was a constant factor throughout the 20th century, with only a slight decline in the last decade. Nonetheless, at the beginning of the century population growth was much less acute than from the 1950s onwards (Figure 3).

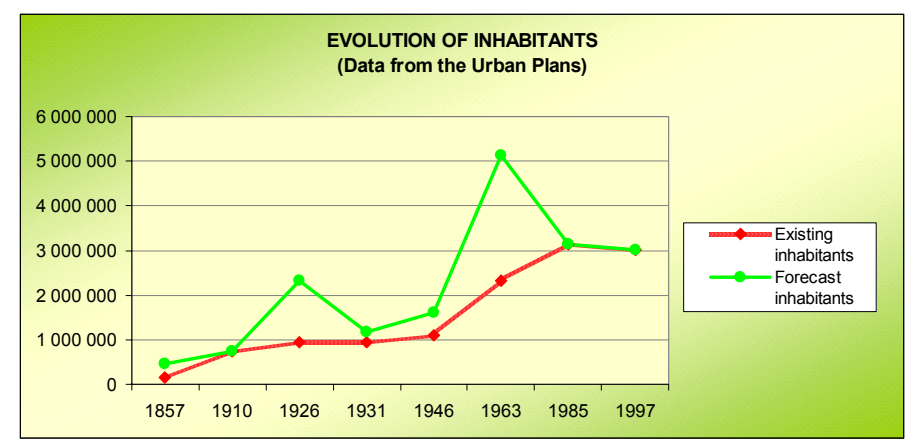

Figure 3: Inhabitants according to each plan.

The Existing Service Index presents clearly defined maxima (Table 4) in the middle third of the century, and significant minima in two very different periods - one during the 1920s and the other in 1985, at the beginning of the return to democracy in Spain. The maxima correspond to the incorporation of large existing wooded areas to the greenspace system (Casa de Campo 1931, Monte de Pardo 1963) and the still low demographic pressure on Madrid. The minima are the result of long periods (1857-1931 and 1946-1985) in which two factors coincided - rapid population growth, and a lack of planning actions with respect to greenspaces.

\section{Table 4: $\quad$ Service indices.}

\begin{tabular}{|l|c|c|c|c|c|c|c|c|c|}
\hline \begin{tabular}{c} 
SERVICE INDICES \\
\multicolumn{1}{|c|}{$\boldsymbol{m}^{2}$ /inhabitant }
\end{tabular} & $\mathbf{1 8 5 7}$ & $\mathbf{1 9 1 0}$ & $\mathbf{1 9 2 6}$ & $\mathbf{1 9 3 1}$ & $\mathbf{1 9 4 6}$ & $\mathbf{1 9 6 3}$ & $\mathbf{1 9 8 5}$ & $\mathbf{1 9 9 7}$ \\
\hline Existing service index & 12.0 & 4.4 & 3.5 & 24.8 & 21.7 & 42.5 & 9.1 & 15.2 \\
\hline Proposed service index & 10.0 & 5.8 & 8.1 & 23.8 & 168.2 & 49.2 & 17.2 & 38.7 \\
\hline Service expectation index & 28.6 & 5.8 & 19.8 & 29.4 & 250.0 & 109.1 & 17.2 & 38.7 \\
\hline
\end{tabular}


The evolution of the Proposed Service Index shows improvement throughout the century (Figure 4), except for the Plans of 1910 and 1926. The maximum also occurs halfway through the century. Of all the Plans, those of 1946 and 1963 proposed by far the greatest greenspace areas (Table 1). At the beginning of the 1950s, however, Madrid underwent excessive population growth, which led to the 1963 Plan being far more ambitious in its projected population figures (Figure 3) than the 1946 Plan. The Proposed Service Index therefore falls sharply despite the Plan for 1963 considerably increasing the proposed total amount of greenspace.

The truly transforming Plans were those in which the Current Service Index is very different from the Proposed Service Index. These were 1931, 1946, and 1963. Nonetheless, the data mask the real situations of 1931 and 1963, since these Plans incorporated existing wooded areas into their greenspace proposals (Casa de Campo, Monte de Pardo).

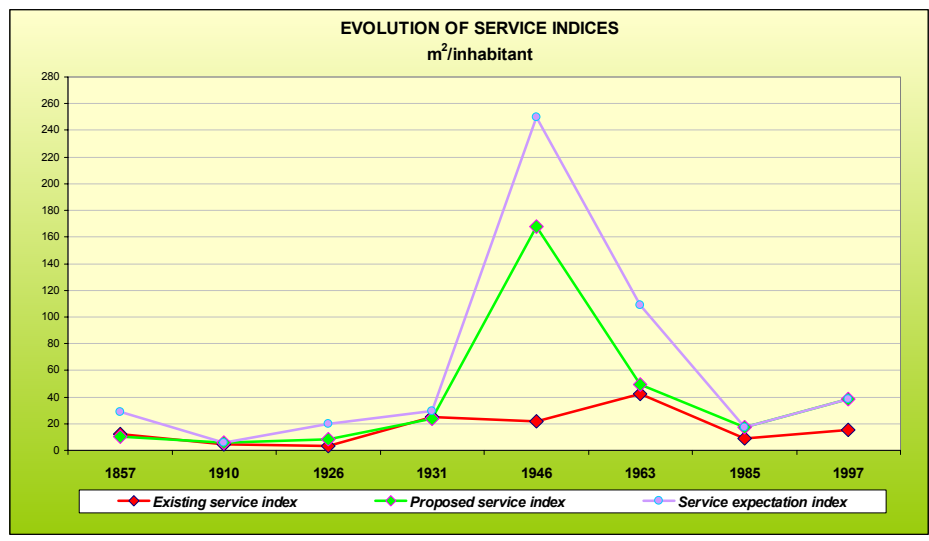

Figure 4: Evolution of the service indices.

The purpose of the Service Expectation Index is to attempt to form a hypothesis of what the implementation of the Plan would have represented at the time of its publication, namely, the expectation that the Plan would have given rise to for the city's inhabitants. Thus, the greater the distance of this index from the Proposed Index, the more significant the difference, and this occurs precisely in the Plans whose projected populations were very different from the population current at the time $(1857,1926,1946,1963)$.

\subsubsection{Comparison between the service indices and the population density}

The projected population density, and its comparison with the service indices, helps to understand the territorial model that underlay each Plan. What is really being compared in each proposal is the amount of greenspace as against the amount of urban land available to each inhabitant.

To calculate this index, we took as the urban area that given in the Plan's proposal, including the area allocated to greenspaces. One observes that there was a radical change in the urban model of the Plans 1946 and 1963 (Figure 5). 
Table 5: $\quad$ Urban area index.

\begin{tabular}{|l|c|c|c|c|c|c|r|r|}
\hline $\begin{array}{c}\text { URBAN AREA INDEX } \\
m^{2} \text { /inhabitant }\end{array}$ & \multicolumn{2}{|c|}{$\mathbf{1 8 5 7} 1910$} & $\mathbf{1 9 2 6}$ & $\mathbf{1 9 3 1}$ & $\mathbf{1 9 4 6}$ & $\mathbf{1 9 6 3}$ & $\mathbf{1 9 8 5}$ & $\mathbf{1 9 9 7}$ \\
\hline Forecast inhabitants & 450000 & 750896 & 2336000 & 1175687 & 1618435 & 5136783 & 3142379 & 3011215 \\
\hline Proposed urban area & 22940000 & 48846579 & 217579800 & 81714410 & 132800040 & 235328260 & 247113986 & 380527482 \\
\hline Urban area index & $\mathbf{5 1}$ & $\mathbf{6 5}$ & $\mathbf{9 3}$ & $\mathbf{7 0}$ & $\mathbf{8 2}$ & $\mathbf{4 6}$ & $\mathbf{7 9}$ & $\mathbf{1 2 6}$ \\
\hline
\end{tabular}

Initially, an expansion was planned which tripled the city's urban area. It nevertheless gave the lowest level of urban area available per capita (Table 5). The first plans of the 20th century increased this area and, in response to the experience in population growth and the consequent overcrowding which had been met with passive acceptance for decades (1857-1910), the proposals are more ambitious.

The Madrid Extension Plan of 1926 overtly expressed the need for a change in model, and proposed a territorial model in which the city would cease to grow in a compact manner, and would extend out into the surrounding territory. Nevertheless, during the first third of the century, the amount of proposed urban area is far above the greenspaces allocated to each inhabitant (Figure 5). In the Plan Castro (1857), the curves are very close together, meaning that the proposed city might be densely or sparsely inhabited, but, whatever the case, it would be perceived as very green. In the following Plans, however, the concern was to significantly increase the available per capita urban area, but not the greenspaces whose per capita amount was considerably reduced.

In 1931, there was a significant change. The planners proposed a slightly different model, with increasing population density, but providing a greater amount of greenspace (Figure 5). In other words, the citizen would perceive a denser city but with more greenspaces. In this particular case, the perception was more symbolic than real, since the increase in the greenspace index is due to the incorporation of the 1700 ha of the Casa de Campo. On the one hand, this was an emblematic incorporation for the society of the time, since it made available to the people what had until then been for the exclusive enjoyment of kings. But on the other, as it was external and a single contiguous estate, it provided very little real accessibility to the people and made for a highly uneven distribution of greenspaces in the city.

In the 1946 Plan, there is a complete transformation in the city model. The greenspaces are no longer a part of the city, but surround and delimit it. The case now is that built-up spaces open breaches into a green territory. More than 27 000 ha of greenspaces were proposed for urban nuclei (core city and satellite nuclei) that occupy approximately 13000 ha (Tables 1 and 5).

The "Plan de Ordenación del Área Metropolitana de Madrid" (Madrid Metropolitan Area Development Plan) changed the situation somewhat, although it remained territorial in nature. Indeed, it is the only Plan for Madrid with a metropolitan scope. The philosophy of green rings and wedges, and of a core city and satellites, is similar to that of 1946 , but it had to address an exaggerated population growth which had not been envisaged by the Plan of 1946, and that had transformed the city. The proposed urban area is, rather than an aspiration, a 
consolidation of an irregular situation caused by illegal construction activities conducted outside the provisions of the previous Plan. Thus, although the philosophy of the Plan maintains a similar model to, and indeed declares itself a continuation of, the 1946 Plan, it is clear that it had no choice but to make contact with a reality that was far from the previously established proposals, and to accept and incorporate this reality into its new proposals. Thus, there are some 25000 ha of greenspaces proposed (Table 1), slightly less than in 1946, but the fundamental difference lies in the 23500 ha of urban land proposed (Table 5). Clearly, the sense behind this figure is that the projected population for whom services were expected to be provided had increased from just over 1.5 million to more than 5 million (Table 5).

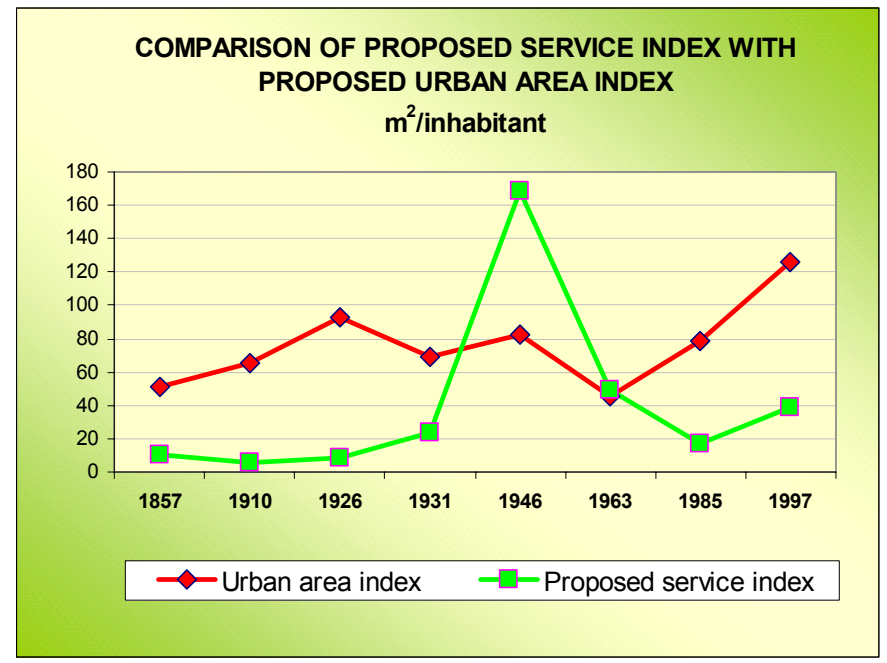

Figure 5: Service index vs urban area.

The sharp drop in the service index from 1963 to 1985 (Figure 5) is due to the closure as spaces of public use of Monte de Pardo, Valdelatas, and some other greenspaces. There is an improvement, however, in the population density. Moreover, the two indices of the 1985 Plan are very similar to those of 1931 (Figure 5), even though the corresponding proposals were very different (Figure 1): the 1985 Plan was characterized by very many small greenspaces distributed throughout the city, while in 1931 the great proposal was the Casa de Campo.

The 1997 Plan makes all vacant municipal land urbanizable, thereby increasing the area of urban land by more than 13000 ha. The text of the Plan makes no reference whatsoever to the projected population. For this reason, the two indices are calculated assuming the population to be constant. With the model proposed, therefore, the analysis will not conform to reality since, when the greenspaces increase, they will do so because some sector of the city has been built up, and this implies some growth in the population. 


\section{Conclusions}

The amount of greenspace in Madrid proposed by the city's successive Urban Plans increased over the course of the century, although the maximum did not correspond to recent years, but to the mid-century. The Plans of 1946 and 1963 proposed an amount of greenspace that was an order of magnitude higher than any other Plan, an aspect that shows the importance that the planners of the middle third of the century assigned to greenspaces.

Nonetheless, there was no relationship between the proposals of the Territorial Plans and the greenspaces that were actually created. Moreover, there appears the paradoxical situation that the period of minimum creation of new greenspaces was the same as that of the proposed maxima.

There was a strong influence of pre-existing greenspaces on the service index. The case of the Casa de Campo is still relevant today. Thus, of the $15 \mathrm{~m} 2$ per inhabitant existing in 1997, $6 \mathrm{~m} 2$ belonged to the Casa de Campo, and when this was ceded to the people of Madrid in 1931, the service index reached almost 22 $\mathrm{m} 2$ per inhabitant.

\section{References}

[1] Alonso, J. M., Ciudad y espacios verdes. Mº de la Vivienda. Madrid. 1971

[2] Cubillo, L., Diseño y optimización funcional de las zonas verdes urbanas. Mo de Obras públicas y Urbanismo. Madrid. 1970-1980?

[3] Rodríguez-Avial, L., Zonas verdes y espacios libres en la ciudad. Instituto de Estudios de Administración Local. Madrid. 1982.

[4] Floresa, A. Adopting a modern ecological view of the metropolitan landscape. Landscape and Urban Planning 39, pp. 295-308, 1998

[5] Salvador, P. J., La planificación verde en las ciudades. Gustavo Gili. 2003.

[6] Van Herzele, A., Wiedemann, T., A monitoring tool for the provision of accessible and attractive urban green spaces. Landscape and Urban Planning 63, pp. 109-126, 2003

[7] Bonaiuto, M., Fornara, F., Bonnes, M., Indexes of perceived residential environment quality and neighbourhood attachment in urban environments. Landscape and Urban Planning 65, pp. 41-52, 2003

[8] Van den Dobbelsteena, A., de Wilde, S., Space use optimisation and sustainability-environmental assessment of space use concepts. Journal of Environmental Management 73, pp. 81-89, 2004

[9] Zhang, L., Wanga, H., Planning an ecological network of Xiamen Island (China) using landscape metrics and network analysis. Landscape and Urban Planning 78, pp. 449-456, 2006

[10] Oh, K., Jeong, S., Assessing the spatial distribution of urban parks using GIS. Landscape and Urban Planning 82, pp. 25-32, 2007 